\title{
Songs of America: A Review of John Berryman's Public Vision by Philip Coleman (Dublin: UCD P, 2014)
}

Asked about his reaction to being classed as "confessional," Berryman described his response as one of "rage and contempt," adding: "The word doesn't mean anything. I understand the confessional to be a place where you go and talk with a priest. I personally haven't been to confession since I was twelve" (qtd. in Stitt 21). It is wise to approach anythingJohn Berryman says about his own writing with a fair degree of suspicion (he seems to reveal more about his poetry when he discusses the work of others) but this kind of reaction clearly indicates a skepticism about reductive critical classifications in general, and a suspicion regarding the specific category. A thorough interrogation of the latter "both with regard to the poet's critical reception and in terms of the more general development of AngloAmerican criticism since the 1970s" (xv) informs Philip Coleman's 2014 book whose aim is to relocate "the scene of disorder" (a formulation used originally in Berryman's "Formal Elegy" for JFK) from the poet's psyche to the sphere of contemporary American realities, and posit Berryman's public vision as "a central aspect of his lasting achievement" (209).

Before he proceeds to examine the extent of Berryman's allusions and engagement with several urgent contexts of its composition, Coleman focuses on the pervasiveness of the disputed designation in the literary critical discourse, and its contribution to the status of confessional poetry as art which fails to engage with the public sphere: starting perhaps as early as M. L. Rosenthal's oft (and rather selectively) quoted view of Robert Lowell's Life Studies as a "magnificent but unpleasantly egocentric" display of personal faults, through Marjorie Perloff's assessment of Berryman's work as an example of the aesthetics of "non-engagement," "confessional" seems to have evolved into a vaguely dismissive term for the "less poetic" kind of poetry whose main purpose is to provide a key to the tortured private life of the poet. 
The highly problematic nature of the classification itself, and of the very distinction between the poetic and the confessional, has already been acknowledged, to some degree: Steven K. Hoffman notes, for instance, that even if the

\begin{abstract}
standard Freudian position does indeed have a validity, it certainly does not help to distinguish the confessionals from any other lyric poets, who also release potentially explosive personal issues in the act of composition. In addition, when applied specifically to the confessionals, it has tended to seriously obscure the degree to which conscious craft determines this literary endeavour. (706)
\end{abstract}

Jo Gill proposes to view confessional writing as "a ritualized technique" which "constructs rather than reflects some pre-textual truth" (4) but the notions of confessional school or confessional aesthetic, Coleman points out, continue to cause confusion and, in general, negatively affect the perception "of mid-century American poetry's meaning and value" (5). Although in his assessment of Lowell's 1959 volume Rosenthal does acknowledge that the poems carry "the burden of the age with them" (qtd. in Coleman 5), socio-political concern

has frequently been ignored in the critical appraisals of the so called confessional poets, and especially in the studies of Berryman and Sylvia Plath. The critical failure to recognize the importance of social, political and historical issues in their poetry has been damaging to the popular and academic perception of a large group of poets ... (Coleman 5)

John Berryman's Public Vision interrogates and reappraises the value of the "confessional" label and re-reads Berryman's poetic output, from the early poems written between 1938-48 to the ones included in the 1972 Love and Fame, revealing the poet's keen interest in the state of American identity, as well as contemporary social and political realities overshadowed by the memory of two world wars, the nuclear threat, the Vietnam war, political paranoia, cultural tensions, and an overwhelming sense of loss and dispossession. Coleman concludes the first part of the book with a nuanced reading of "Formal Elegy"-where "Berryman is concerned to break down certain borders and boundaries-of form, genre, self/ other, past, present and future between the private and public, state and citizen" (42)—creating a critical "lens" through which the poet's further engagements with the public sphere will be reviewed.

Important encounters with W. B. Yeats ("I have moved to Dublin to have it out with you, majestic Shade," Berryman writes in DS 312), leftwing protest painter Ben Shahn (who supplied illustrations for the 1956 
edition of Homage to Mistress Bradstreet) and communist poet and close friend Robert Bhain Campbell (mentioned, among others, in "Dream Song 88," alongside Yeats, as one of the "violent dead" whose "awful brains" Henry wants to pick), are examined and re-problematized in this thoroughly researched study. So is Berryman's ceaseless ambition to "think barder in verse," which he vowed in a note on a manuscript of one of the poems (emphasis original). Coleman's attentiveness to Berryman's "selfconscious delight in language (not least in his use of a word like 'frore,' as highlighted in his note, but also 'thews,' 'repine' and 'belvedere')," evident in his treatment of the poet's notoriously difficult syntax and radical stylistic experimentation, mirroring, perhaps, Berryman's own profound attention to the word, results in a series of convincing readings of texts intended to "give aesthetic pleasure in proportion to the complexity of [their] argument" (79). What is particularly satisfying about Coleman's analysis is that he traces the development of the poet's public vision throughout the entire oewore, from the "poetics of survival" located in Berryman's early work, the "nightmares of Eden" resurfacing in the texts from the post-war decade, "cinematic vision and epistolary projection," and the themes of displacement in The Dream Songs, to the "questions of priesthood \& of State" in Love and Fame. The book concludes with a commentary on Berryman's presence in Irish literary culture of the 1970s and a brief discussion of his contemporary influence on both sides of the Atlantic.

Accompanied by a discussion of his published and previously unpublished work, correspondence, essays and notes held at the University of Minnesota, Coleman's readings succeed in showing Berryman as a poet both deeply committed to technical innovation and continuously aware of the volatile "outside" reality in a hope that the former may help negotiate or at least register the perplexing experience of being in the world. At the same time, John Berryman's Public Vision is a persuasive and forceful intervention in the state of research not only on the author of The Dream Songs but also mid-century American poetry in general, a stimulating and highly readable piece of criticism which is likely to become an important reference for Berryman readers and scholars.

\section{Works Cited}

Berryman, John. The Dream Songs. New York: Farrar, Straus and Giroux. 2007. Print.

Coleman, Philip. John Berryman's Public Vision: Relocating the Scene of Disorder. Dublin: UCD P, 2014. Print. 
Gill, Jo, ed. Introduction. Modern Confessional Writing. New Critical Essays. New York: Routledge, 2009. 1-10. Print.

Hoffman, Steven K. "Impersonal Personalism: The Making of a Confessional Poetic.” ELH 45.4 (Winter 1978): 687-709. JSTOR. Web. 12 July 2017.

Stitt, Peter. "An Interview with John Berryman.” Berryman's Understanding. Ed. Harry Thomas. Boston: Northeastern UP, 1988. 18-44. Print.

Anna Warso is Assistant Professor in the Department of English at the University of Social Sciences and Humanities in Warsaw where she teaches courses in American literature and workshops in translation. She wrote her doctoral dissertation on the figurations of loss in John Berryman's The Dream Songs and her research interests include, among others, $20^{\text {th }}$-century American poetry and literary translation. She has published essays and articles on the work of John Berryman, Elizabeth Bishop and John Ashbery, she is also the co-editor, with Agnieszka Pantuchowicz, of the forthcoming Culture(s) and Authenticity: The Politics of Translation and the Poetics of Imitation and Interpreting Authenticity: Translation and Its Others (Peter Lang).

awarso@swps.edu.pl 


\section{Yeats, Incorrigibly Plural. A Review of Barry Shiels's W. B. Yeats and World Literature: The Subject of Poetry (Farnham: Ashgate, 2015)}

In his W. B. Yeats and World Literature, Barry Shiels states his purpose sharply: "This book is the first study of Yeats's poetic modernity to scrutinise within his writing the relations between the order of poetic expression and the effects of money, trade and globalisation" (3). Bold though the claim may appear, it is in fact a pioneering attempt to embrace in the process of reading the Pollexfen side to Yeats. W. B. Yeats's well-known but no less crisp insight, that in marrying Mary Pollexfen he, a descendant of a gregarious but impoverished family, gave "a voice to the sea-cliffs" (Jeffares 24), has long circulated among the poet's biographers though nobody really set much store by it. There have been suggestions, early on by Richard Ellmann and more recently by R. F. Foster, that, as a shrewd theatre manager and self-promotor, Yeats relied on the business-capable Pollexfen in him, not the prodigal Yeats strain (see Foster 9-10). One is, for example, reminded of how skilfully Yeats handled his copyright in both the UK and the U.S., at the same time using his business acumen to keep his sisters' press solvent. In fairness to Shiels, it must be admitted that no one has interrogated Yeats's understanding of money matters as part of his poetic practice although the rather meticulous explorations of the publishing history of his books give one a good idea of how successfully he managed as prosaic an aspect of his life as finances. Still, reading Yeats against the background of global monetary policies is a project little covered by the substantial Yeats criticism.

In spite of the declared thesis of his monograph, Shiels evokes a wider picture of Yeats as caught between avowed traditionalism and a deep awareness of the developments of international modernism as concomitant of the larger process of modernity. One of the earliest expressions of this tension is that between what Shiels refers to as the "sub-national" and the "supranational" 
affiliations of Yeats: "at one level Ireland [in a poem like 'An Irish Airman Foresees His Death'] is essentially local, immanent, minoritarian in ethos and always falling short of full national sovereignty; at the other level it is a movement of transnational flight and essentially diasporic in nature" (3031). The former aspect remains a still better-known facet of Yeats's literary production, although an increasing body of scholarship points to Yeats's involvement in the development of transnational character of modernism. Instead, however, of rehashing the familiar terrain of Yeats's exposure to the Far East and his keenness to elaborate a form of ritual drama that would take stock of the Japanese noh tradition, Shiels pays attention to aspects of Yeats's cenvre that have hardly been considered. Notably, "The Song of the Happy Shepherd" and the follow-up "The Sad Song" are both given as examples of "telephonic technology," which would have underscored the feelings of spatial and temporal dislocation: "The modernist writer is forced to acknowledge that his language is thrown into an indefinite space-a space in-between-within which it can be distorted, interfered with, contracted by speed, its words elongated" (41). The "telephonic" effect of "echo-harbouring" (41) does indeed work in some of Yeats's best poems, particularly "Man and the Echo," and one feels that a man who never shunned the benefits of technology, like cars, electric light, the telegraph and the telephone (one of the things he had installed in the Rathfarnham house, where he moved with his family in 1932, was a telephone), must have appreciated the effect that his poems created.

Yet the traditionalist side to Yeats is duly noted and given some treatment. Still, Shiels is quick to note that even when Yeats trumpets his allegiance to tradition, as in the "General Introduction for My Work" where he states "I must choose a traditional stanza, even what I alter must seem traditional" (Yeats, Later Essays 213), this is "a frank acceptance that it is the 'original' work of an individualised modern author" (Shiels 58). This individuality, however, is not ascribed to the Romantic perception of the poet as legislator of the world but rather to the promulgation of the copyright law, which had been stipulated by a number of government acts between 1896 and 1911. Given Yeats's awareness of how to ensure that copyright remained with him for both the UK and the U.S. editions of his works, Shiels's point is crucial to our understanding of the sense of individuality that Yeats seems to have cherished.

Having shown Yeats's tricky affiliation with tradition and traditionalism, Shiels focuses on the poet's perception of other indigenous cultures. Taking his cue from Herder, he argues for a more nuanced idea of folk culture than just a set of beliefs that are inherited from generation to generation, the latter position only seemingly resonant with Yeats's own understanding of folk culture; as Shiels adequately puts it, "no folk tradition is complete to itself but rather exists in combination with its other, usually 
the folklorist or anthropologist; moreover, it is this imperfect relation that accounts for a tradition of the verb, of call and response, over the noun" (88). This is a pertinent claim in that Yeats realized that the tradition which is handed down to the poet is in no sense a stable set either in the sense that it comprises a definitive number of tales and beliefs or that the tales follow a prescribed plotline. As early as in the series of articles on faerydom that ran between 1897 and 1902, Yeats continuously implies that the ideas he expounds on represent certain popular variants but do not aspire to lay down the definitive edition.

Yeats's (and Gregory's) quest for reinstating the traditional beliefs of Ireland in the contemporary context is beset with various quarrels he engaged in on behalf of his views. Shiels goes back to some of the betterknown ones but does manage to shed some interesting new light on them. This is the case with the disagreement that Yeats had with Douglas Hyde in 1892 over his paper "The Necessity for De-Anglicizing Ireland," in which Hyde argued for the need to bring back Celtic as the first language in Irish life, including literature. Yeats responded by claiming that the "continuity of the nation's life" would best be preserved "by translating or retelling in English, which shall have an indefinable Irish quality of rythm [sic] and style, all that is best of the ancient literature" (Yeats, Uncollected Prose 255). Shiels observes that in so positioning himself, Yeats's idea is underlain with a polarity, whereby "a tradition based upon the qualities of 'translating and retelling' invariably mourns its lost origin yet remains in its expressive life unauthenticated and uninhabited by the idea of original perfection" (91). This strikes a pertinent note, for Yeats's theoretical pronouncements on the nature of poetry and its applicability to social praxis recurrently show him to both endorse the view that tradition is a prerequisite for the development of a nation and to refute the idea that this tradition is an unshakeable dome, as in Eliot, that must be paid obeisance to by the budding poet. Critics like Ronald Schuchard in his magisterial The Last Minstrels have shown that Yeats's ideas about tradition and originality assume a fixity of perfection available as a fleeting insight but then represent variation and an ad hoc implementation when actualized in a poem or oral performance. Shiels draws a parallel between Yeats's own retellings of Irish folk tales in The Celtic Twilight and "ironically picaresque" stories and Borges's detective fiction, in which he would "conjure the spirit of vast encyclopaedic projects whose indices continually defer the secret knowledge they promise" (Shiels 96). This nicely captures the implicit spirit in which Yeats wrote his Celtic Twilight stories, all of which exude an aura of locality and fleetingness rather than authority and completeness.

Towards the end of his study, Shiels approaches Yeats's last writings, a difficult territory for anyone willing to suggest that Yeats was less of an 
authoritarian, at least in his work, than critics like W. J. McCormack would have him be. The strategy Shiels adopts when dealing with the last poems and $O n$ the Boiler emphasizes "concealment amidst the diverse forms of his expression" (177) such as he practises in the later poems, plays and essays, all of which maintain a balance of various views. For Shiels, Yeats never falls for the trap of politics, which is "bound to ressentiment as the identification of expression with the content of subjective demands," instead, he is "the subject who is willing to repeal his very subjectivity and withdraw the grounds for argumentation" (177). Such an approach to Yeats's late writings seems more fruitful than asserting that poems like "Man and the Echo" and "Circus Animals' Desertion" are mere disguises for a poet inherently keen to " $[\mathrm{s}]$ corn the sort now growing up / All out of shape from toe to top" (Yeats, Poems 327).

Whereas he occasionally fails to take full stock of the subversive potential implicit in On the Boiler or poems like "Under Ben Bulben," in which Yeats drops hints that politics will forever remain inferior to literature, never reaching the level of complexity of the poetic text (one is reminded of the peculiar ending to his last pamphlet), Shiels offers a sustained and thorough reading of Yeats as poet, playwright and theoretician of literature. By stressing the international context of Yeats's interests, in folk, other literary traditions and the cultural politics of Ireland and Europe (as much from the theoretical as from the practical point of view), he achieves a level of critical insight that a specialist and a layman alike will find appealing.

\section{Works CiTED}

Foster, Roy F. W. B. Yeats: A Biography. Volume 1: Apprentice-Mage. Oxford: Clarendon, 1999. Print.

Jeffares, A. Norman. W. B. Yeats: A New Biography. London: Continuum, 2001. Print.

Yeats, W. B. The Collected Works of W. B. Yeats. Volume I: The Poems. Ed. Richard J. Finneran. New York: Scribner, 1996. Print.

---. The Collected Works of W. B. Yeats. Volume V: Later Essays. Ed. William H. O’Donnell. New York: Scribner, 1994. Print.

---. Uncollected Prose. Volume 1. Ed. John P. Frayne. New York: Columbia UP, 1970. Print. 
Wit Pietrzak is Professor of British and Irish Literature in the Institute of English Studies, University of Łódź. He specializes in modernist and neo-modernist Irish and British poetry and has published several books of criticism, including Levity of Design. Man and Modernity in the Poetry of J. H. Prynne, Ostrożnie, poezja. Szkice o wspótczesnej poezji anglojezzycznej [Careful, Poetry. Essays on English-Language Poetry] and most recently The Critical Thought of W. B. Yeats.

witpietrzak@wp.pl 


\section{Katarzyna Ojrzyńska}

University of Łódź

\section{"Disability demands a story": A Review of Stewart Parker's Hopdance (ed. Marilynn Richtarik, Dublin: Lilliput, 2017)}

In most of his literary works, the acclaimed Northern Irish poet and playwright Stewart Parker did not allude to his experience of disability as an amputee. Thus, his recently published short novel Hopdance, edited by his biographer Marilynn Richtarik, can be seen as Parker's posthumous act of "coming out" as a disabled writer, rather than a writer with a disability. I have used the former term intentionally to underscore the fact that the novel, taking inspiration from the Joycean literary tradition of autobiographical comingof-age narrative, presents the disability experience of the protagonist, Tosh, the author's alter ego, in the form of a journey of personal and artistic selfdiscovery. Hence, disability is not the main character's secondary feature, but it serves as an acquired characteristic that defines Tosh as a person and an artist, and as the main motif in the novel.

"[D] isability demands a story" (43), writes Michael Bérubé, commenting on David T. Mitchell and Sharon L. Snyder's seminal work in which they argue that "disability has functioned throughout history as one of the most marked and remarked upon differences that originates the act of storytelling" (54). This demand for a story is most conspicuous in everyday interactions in which a departure from the bodily norm prompts questions about the cause and origins of a bodily variation which often has the form of an impairment. The stories told in response to questions such as "What's happened to you?" have often been used in contemporary culture so as to reinforce the prevalent ableist narratives about disability. These narratives frequently approach disability from a medical perspective, according to which impairment is a defect, an abnormality, and an essentially negative condition that needs healing. Alternatively, an impairment can be overcome when the impaired person discovers some "special" talent which can be the source of his or her success "in spite" of the physical (or mental) 
“limitations." Tosh's journey does not easily fit within such conventional narrative models.

Depicting the acquired impairment as a traumatic and life-changing experience, the novel was considered by Parker to be unfinished. Explaining the nature of her editorial work on its text, Richtarik states: "Upon Parker's death, Hopdance consisted of a few sequences of scenes typed at various times, the remaining scenes (most of them) still in manuscript, and handwritten notes regarding the order in which these vignettes should appear" ("Stewart Parker's Life Story"). On the basis of Parker's notes, these episodic scenes have been arranged in a non-linear way that still makes the narrative progress coherently, first towards the climactic moment of amputation, and then towards an important scene of denouement. In terms of structure, the two episodes that frame the narrative are of particular importance. The novel opens with the description of the moment of confrontation when Tosh looks into the mirror after the surgery and does not identify with what he sees in it— "Scary ghost. Sad freak.... halt scarecrow." What pervades the following episodes is a sense of displacement to a new body and a new world outside the hospital, which once used to be safe and familiar, but now, seen from the perspective of an amputee, inspires deeply uncanny feelings.

The subsequent, non-chronological episodes progress towards a powerful conclusion-a poignant moment of self-awareness and selfacceptance when Tosh meets a beggar who, much like himself, is an amputee. The old man presents him with a question which is strongly linked with the experience of disability. After their mutual visual recognition, the beggar demands a story, asking: "What's your story, son?" The act of verbalizing the story of his bodily transformation has a therapeutic value for Tosh. It is a way of working through his traumatic experience and a means of achieving peace. Yet this episode and the whole novel alike are about much more than just overcoming trauma through self-expression. Most importantly, Hopdance offers a narrative about a man who becomes a storyteller - a process facilitated by the experience of disability which gives Tosh a new perspective on his life and the surrounding reality. In her biography of Parker, Richtarik comments on the liberating aspect of such experience. She explains that in a conversation with a friend the writer stated that "before the discovery of his cancer, the only amputees he had ever noticed were beggars" and thus later developed a conviction that "he would also be poor." Consequently, Parker's decision to become a writer-"an utterly impractical career choice"-was, according to Richtarik, mostly motivated by his belief that all amputees are doomed to material deprivation (Stewart Parker). Yet what emanates from Tosh's encounter with the beggar is more than a sense of occupying the social 
margin which, in the protagonist's case, is a place that enables a distanced and deep insight into the surrounding world. The idea of homelessness, often connected with a nomadic lifestyle, when combined with the oral tradition, also brings to one's mind an instant association with the Gaelic seanchai (the traditional Irish storyteller). All this indicates that Tosh's impairment serves as an enabling, rather than a disabling, experience which facilitates a discovery of a new way of being in the world and can be seen as an initiation into the world of Irish storytelling and literature.

Having in mind the vibrant presence of disability arts in Ireland and their significant development in recent decades, as well as Irish disability activism which, especially since the 1990 s, has greatly contributed to the dynamically changing local attitudes to disability, Parker's Hopdance is a timely and important novel. The person who deserves special acclaim for bringing it to light is Marilynn Richtarik whose meticulous editorial work helps the reader to examine the development of the novel, which was initially intended as a screenplay. The editor's note on the text and her appendices which trace the revisions in the order of the scenes that Parker introduced to the initial draft are particularly helpful in this respect, while the foreword written by the artistic director of Rough Magic Theatre Company (which has staged a number of Parker's plays, including Pentecost and Northern Star) and Parker's niece —Lynne Parker-adds a personal touch to the novel. All of this makes Hopdance a worthy and needed contribution to the Irish literary canon.

\section{Works Cited}

Bérubé, Michael. The Secret Lives of Stories. New York: New York UP, 2016. Print.

Mitchell, David T., and Sharon L. Snyder. Narrative Prosthesis: Disability and the Dependencies of Discourse. Ann Arbor: U of Michigan P, 2000. Print.

Parker, Stewart. Hopdance. Ed. Marilynn Richtarik. Dublin: Lilliput, 2017. Kindle file.

Richtarik, Marilynn. Stewart Parker: A Life. Oxford: Oxford UP, 2012. Kindle file.

---. "Stewart Parker's Life Story Gets One Last Act.” Irishtimes.com. The Irish Times 12 May 2017. Web. 18 Nov. 2017. 


\section{Building Bridges: \\ From Łódź to Ulster and Back \\ Jadwiga Uchman \\ Interviews Jan Jędrzejewski}

Jadwiga Uchman: Jan, I'm very glad to see you in Poland again, even though I meet you quite often in Ulster, or Coleraine, to be specific, because of the exchange between the two universities. We met for the first time when both of us were working in the Institute of English Studies in Łódź. You got a scholarship to Oxford, and then-what happened?

Jan Jędrzejewski: Yes, I was a teaching assistant at the University of Łódź from 1984, and then, in 1987, I was lucky enough to get a scholarship to Oxford, which was funded by the Soros Foundation for postgraduate, or rather pre-doctoral, students, from Poland and Hungary. There were several of those scholarships awarded to people from across Poland, and I was lucky enough to get one as the only person from Łódź in the group. I spent that academic year, from September 1987 to July 1988, as a postgraduate visiting student at Worcester College, Oxford. During that year, I was not studying towards an Oxford degree (I was at that stage still planning to submit my doctorate to the University of Łódź), but I had a chance to do research towards my doctorate and also broaden my general knowledge and experience of anything to do with British literature, culture, life and institutions-well, anything to do with Britain-during that period. That lasted for ten months and then I went back to Poland. In the meantime, towards the end of that year at Oxford, a number of us, members of the scholarship group, started looking for ways of trying to turn this visiting scholarship into something more long-term, hopefully with a view to obtaining our doctorates from Oxford. A number of my fellow students succeeded in achieving that.

JU: As did you.

JJ: Yes. It took me longer than others to get this full doctoral scholarship, so I came back to Poland for the academic year 1988-89, and then I went back to Oxford in the autumn of 1989. I stayed there for three and a half years, working on my doctorate. 
JU: Did you have an English or a Polish supervisor?

JJ: When I was registered while I was a teaching assistant in Łódź, I was supervised by Professor Adela Styczyńska, as any young staff member would have been supervised by a senior colleague. But when I went to Oxford I had a supervisor who was allocated by the University, and I was very privileged to have Professor John Bayley, who was one of the most outstanding literary critics working at Oxford at that time, as my supervisor.

JU: When you got the doctorate, did you return to Poland? Did you go back to teaching?

JJ: I did not return to Poland. In my last year of the DPhil (DPhil is the formal abbreviationfor an Oxford doctorate), I started looking for jobs all over the United Kingdom, and in the summer of 1992, before my doctorate was confirmed, I was lucky enough to be shortlisted and interviewed for a job at the University of Ulster, and I was offered a job there. So, basically, I moved straight from my postgraduate studies at Oxford to a full-time academic position at the University of Ulster, where I started in January 1993.

JU: Did you stay there all the time?

JJ: Yes. I've now been at Ulster for almost twenty five years. I've spent my entire British career there.

JU: There was a wonderful exchange between the University of Ulster and Łódź, thanks to your efforts. At the beginning there was a two week exchange of academic teachers between Ulster and Łódź.

JJ: Yes. The link between Ulster and Łódź was something I always wanted to develop. I was always aware, when I was a student and then a teaching assistant in Łódź, how important it was to have direct links with UK institutions. So when I was able to facilitate this, I felt that it was the right thing to do. I followed the model of some of the previous exchanges we had in Łódź. I made contact with the British Council, and at that point we were lucky enough to have the support of both the British Council office in Warsaw and the British Council office in Belfast. So for ten years or so, between the early 1990s and the early 2000s, we had a British-Councilsponsored link between the two universities, specifically the literature departments of the Institute of English Studies in Łódź and the English 
Department at Coleraine. That arrangement lasted in various forms over a period of about ten years. In the early 2000s, given the changes to financial priorities and arrangements within the British Council, we had to look for an alternative source of funding, and at that time we developed an Erasmus link. For over ten years now, we have had an Erasmus partnership which facilitates the travel of staff and students both ways. So it's been a very fruitful and positive collaboration.

$\mathrm{JU}$ : Were there any other exchanges for young scholars?

JJ: Yes. There was a different scheme from 2001 to 2005, but that was not organized directly between our two universities: it was an initiative that was developed between the then Dean of the Faculty of Arts at Ulster, the late Professor Robert Welch, and the British Council in Warsaw. Basically he devised a scheme whereby the University of Ulster would collaborate with the British Council to facilitate summer visits by young scholars from English departments at Polish universities, who would be either predoctoral or post-doctoral, and who would come to Ulster for about three months over the summer. The British Council paid them a stipend, and the University of Ulster offered them accommodation free of charge, and also ensured access to the library, to computing facilities, and so on. Each year there would be three or four young scholars from various universities in Poland coming to Ulster. The scholarship scheme lasted for five years from 2001 to 2005 and in total, I think, sixteen people from across Poland participated in that programme. Four out of the sixteen came from Łódź, so there was a big proportion of Łódź people. I hasten to add that, given the attractiveness of that programme to people from across Poland, much as I was obviously keen on having people from Łódź, the four people from Łódź who took part in the scheme all won their places on merit, through a competitive mechanism.

JU: The support of the British Council is one thing but your personal involvement is another. I was quite surprised last year when you told me about looking for accommodation for Erasmus students in Eódź while you were here during summer holidays.

JJ: Well, one of the things I suppose I always try to do is to make sure that the people that I work with have as good an experience as possible. We have to remember that the way exchanges tend to work in the United Kingdom is that while there are lots of students wanting to come to the UK, there are not very many UK students actually willing to go abroad unless they are themselves language students and they go to France, 
Germany, or Spain. So trying to send exchange students to Poland is actually quite a demanding job. The experience of studying in a country where the language is difficult, and which is still perceived primarily in its Eastern European context, does not appear so very attractive to British students. My three students who are actually at the University of Eódź this academic year completed the formalities a bit too late to apply for university accommodation. When they discovered they were on the waiting list it wasn't quite clear what they would do, and whether they would eventually get places in university accommodation. I was in Poland then, so it was a decent thing to do to try to help them. It wasn't much of a problem to do a little bit of research to find them places in a student hostel. It only took me a couple of hours.

JU: I wish there were more people like you.

JJ: Well, thank you very much.

JU: You are also very helpful to our academic teachers who come to Ulster on the Erasmus exchange. I can always write to you and you get books through the interlibrary loan system which it would not be easy for me to get during a short stay. It's a great help and not so many people are willing to help nowadays.

JJ: Well, again, it's no big deal. It only takes me a few minutes to fill in an order, and I'm glad to be able to help. I must say I was very lucky when I was a postgraduate in England, and during that time I met some truly fantastic people. They helped me in all sorts of ways, so I now feel I should behave in the same way to others, to return the favour, as it were. It's just the decent thing to do.

JU: This brings us to the medal you received from the University of Łódź last year but were unable to collect then, and you will get it this Wednesday.

JJ: That's correct. The University of Łódź was very generous last year to award me a medal "Universitatis Lodziensis Amico" "To a Friend of the University of Łódź"), and I feel very honoured to have been awarded it. I was not able to come to attend a special meeting of the Senate last year to collect it, so I will get it this year.

JU: Congratulations.

JJ: Thank you very much. 
JU: I was very pleased to hear that you would be getting one. There is another thing: I remember you had not been officially informed about it.

JJ: Yes. I suppose all the various administrative procedures take a while, so yes, I did know "unofficially" that I would be getting it before I knew "officially."

JU: There is one more thing I would like to ask about, namely the question concerning popularizing Polish literature and culture abroad. You told me during our previous meetings about a conversation with Professor Welch and the question of the authorship of a particular poem.

JJ: Well, that goes back to the summer of 1992, when I was interviewed for the job at Ulster. I was supposed to give a presentation, and the title of the presentation was "Issues of Identity in Irish Literary Studies." At that time I knew very little about Irish culture and Irish literature, apart from the standard big names that everybody has read, such as Swift, Yeats, and so on, but little beyond that. So I thought that, maybe, I could try to make a case about some cultural and historical parallels between Ireland and Poland that might serve as a basis which I could use to explore some aspects of Irish identity. I could, perhaps, try to look for Polish texts which, if you changed the word "Polish" to "Irish," could possibly pass for Irish poems, and/or vice versa. I found a perfectly respectable $19^{\text {th }}$-century translation of Mickiewicz's "Do matki Polki" and, as it happened, it actually fitted the cultural context of $19^{\text {th }}$-century Ireland extremely well. So I presented it, with the word "Irish" replacing "Polish" throughout the text, and tried to analyze it at the interview, before identifying it as a Polish poem half way through my presentation. And that enabled me to say a few words about the Irish and Polish identities in the $19^{\text {th }}$ century. Now, little did I know that one of the members of the interview panel, who was then the Chair of the English department at Ulster, Professor Robert Welch, who you referred to, was a specialist in $19^{\text {th }}$-century Irish poetry. Obviously, those were the days before the internet, so it was impossible to check who the people on the interview panel might be. So I just obviously did not know. But, not surprisingly, he was absolutely puzzled to hear, from a candidate from Poland, an analysis of an Irish poem he had never read. Obviously he must have appreciated the trick that I played on him and the rest of the panel, because they offered me the job. Now, I've got to say my perception of Irish culture has changed dramatically in the years I've lived in Northern Ireland, and I suppose if I were to be listening to that presentation now, I would say that there were numerous flaws in my argument. I would also be able to present many more examples, some of them hopefully more sophisticated, both to 
support and to contradict my argument. However, my analysis must have been deemed to be interesting enough because I got the job at the time. I've got a very different view of Ireland now, hopefully somewhat more nuanced and somewhat more insightful, but that is how I started working at Ulster.

JU: As far as I recall there was a Polish link in the lecture which you gave after getting the title of professor.

JJ: Yes. I suppose I did mention that particular job interview because basically my formal title is Professor of English and Comparative Literature, and my professorial lecture was specifically on the advantages of studying comparative literature, so I did talk a little bit about various ways in which comparative literary studies operate. I started off by mentioning my experience of that 1992 interview, and then I finished by playing a similar trick on the audience, this time in relation to a contemporary event. I read a poem, and tried to convince the audience that it was about the invasion of Iraq. However, the poem was a translation of Broniewski's "Bagnet na bron," and the reason I chose it was that if you put yourself in the position of an Iraqi at the time of the American invasion, and if you compare that experience to the experience of the Polish people in 1939, when the German invasion was looming, you notice that the similarities are quite obvious. That, to me, was another way of demonstrating that comparative literary studies may be useful, transferring ideas and perceptions from one culture to another, and thus enriching our thinking and experience. Also, from the rhetorical point of view: given that I had started my lecture with a mention of that job interview from 1992, the Broniewski poem rounded things off nicely, and it seemed that my trick worked again.

JU: You made the lecture available to me and I found it fascinating. I would like to thank you very much for a very interesting interview.

JJ: Thank you very much.

JU: I hope that you will keep coming to Poland and strengthening the links between Poland and Ireland.

\section{JJ: Northern Ireland.}

JU: Northern Ireland. Sorry. Maybe you could come because there is a sequence of lectures in honour of Professor Ostrowski and we invite prominent speakers who are in Poland at the time to give a lecture. So perhaps during one of your future visits you could give a lecture as well. 
I will keep it in my mind and make arrangements to have you as a speaker some time in the future.

JJ: I would be honoured. I was a student of Professor Ostrowski and he taught me a course of lectures on the history of English literature so, yes, I would like to do that.

JU: Thank you once more for a very stimulating interview.

JJ: Not at all.

Jan Jędrzejewski was educated at the University of Łódź, Poland (MA in English philology, 1985), and at Worcester College, University of Oxford (DPhil, 1992). He has taught at the University of Ulster since 1993; he became Senior Lecturer in 2001, and Professor of English and Comparative Literature in 2007. He served as Head of the School of English and History (2009-14), and Dean of the Faculty of Arts (2014-17). A specialist in nineteenth-century English literature, particularly the Victorian novel, Professor Jędrzejewski also has major interests in Irish literature in English and in comparative literature. He has published monographs on Thomas Hardy and the Church (1996) and George Eliot (2007), critical editions of Hardy and Joseph Sheridan Le Fanu, as well as numerous journal articles and book chapters. He is currently involved in revising and updating a multilingual pan-European literary compendium, Lettres Européennes/A History of European Literature. jp.jedrzejewski@ulster.ac.uk 